\title{
Intelligent monitoring and recognition of the short-circuiting gas-metal arc welding process
}

\author{
C S Wu ${ }^{1 *}, \mathbf{Q} X \mathrm{Hu}^{1}, \mathrm{~J} \mathrm{~S} \mathrm{Sun}^{1}, \mathrm{~T} \mathrm{Polte}^{2}$ and D Rehfeldt ${ }^{2}$ \\ ${ }^{1}$ Institute of Materials Joining, Shangdong University, Jinan, People's Republic of China \\ ${ }^{2}$ Department of Materials Joining, University of Hannover, Germany
}

\begin{abstract}
This paper introduces an intelligent system for monitoring and recognition of process disturbances during short-circuiting gas-metal arc welding. It is based on the measured and statistically processed data of welding electrical parameters. A 12-dimensional array of process features is designed to describe various welding conditions and is employed as input vector of the intelligent system. Three methods, such as fuzzy c-means, neural network and fuzzy Kohonen clustering network are used to conduct process monitoring and automatic recognition. The correct recognition rates of these three methods are compared.
\end{abstract}

Keywords: intelligent monitoring, automatic recognition, process disturbance, gas-metal arc welding, short-circuiting

\section{INTRODUCTION}

Gas-metal arc welding (GMAW) is installed in most arc welding robots. Its consumable electrode melts and transfers into the weld pool [1]. Because of the good controllability of droplet size and detachment timing [2], drop spray is typically considered a perfect transfer mode. A conventional pulsed GMAW process uses a peak current higher than the transition current [3] and produces a large arc pressure [4], which is undesirable for welding of sheet metals. In a recent series of studies [5-7], the momentum of an oscillating droplet has been taken advantage of to reduce significantly the peak current. However, during short-circuiting GMAW, the current is small and the transfer is accomplished on the weld pool surface so that the arc pressure is small and the impact of the drop on the weld pool is eliminated. Hence, short-circuiting is more suitable for sheet metal welding [8] where burn-through is a major issue.

Complex physical phenomena occur during shortcircuiting transfer. The process appears dynamic, stochastic and non-linear. Therefore, it is necessary to use an automated monitoring system to recognize process error and/or disturbance to prevent cost-intensive post processing or to avoid defective welds [9]. Various sensors, such as electrical, optical or acoustical sensors, are in use.

\footnotetext{
The MS was received on 21 November 2002 and was accepted after revision for publication on 13 May 2004.

* Corresponding author: MOE Key Lab of Liquid Structure and Heredity of Materials, Institute of Materials Joining, Shangdong University, 73 Jingshi Road, Jinan 250061, People's Republic of China.
}

Looking to the robust and versatile application of a monitoring system, the electrical parameters (welding voltage and current) can be seen as the most appropriate process characterizing parameters. In the transient run of voltage and current, all process information is stored, whereby disturbances can be recognized by variations of well-known transient runs. Because of the complexity of these transients, the captured raw data should be further processed. An effective method can be seen in the application of statistic methods to the non-deterministic stochastic welding process [10]. The description of a stochastic process is possible by means of probability density distributions (PDDs) and class frequency distributions (CFDs) [10-12]. The definitions and descriptions of both PDDs and CFDs have been introduced in detail in the Appendix of a previous paper [13], and so they are not reiterated here. The PDDs and CFDs of welding voltage and current deliver characteristic information of the welding process behaviour. Hence, the identification of process disturbances or failures is enabled by means of PDDs and CFDs, but this is only accomplished with comprehensive expert knowledge which is based on the correlation of physical phenomena and its effect on the regarded distributed variables [11].

For automated recognition the required expert knowledge has to be formulated so that it can be processed by computational algorithms. Artificial intelligence methods should be used. Fuzzy logic and neural network techniques have been adapted for recognizing GMAW process disturbances $[\mathbf{1 2}, \mathbf{1 3}]$, but the correct recognition rate is around 92 per cent. For practical application in 


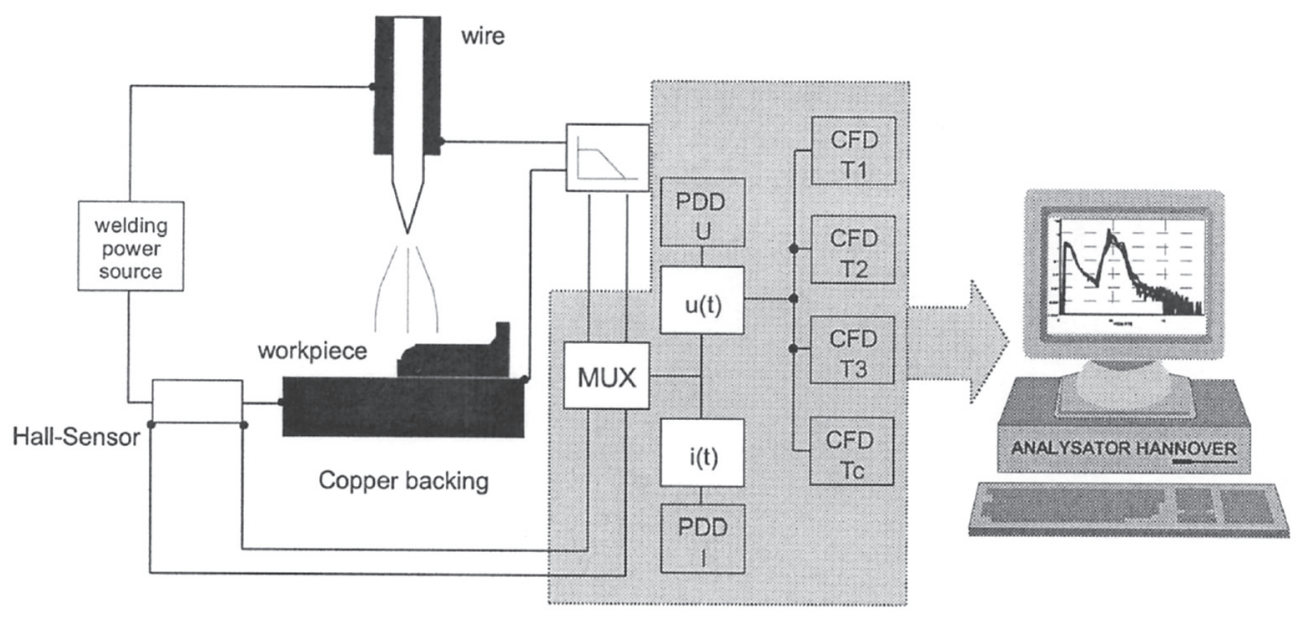

Fig. 1 Block diagram of the measurement set-up

manufacturing, it needs 100 per cent accuracy to ensure weld quality. Therefore, great efforts should be made further in this field. This paper introduces a system which is based on the accurate extraction of process characteristics from PDDs and CFDs, and the combination of fuzzy logic and neural network methods.

\section{EXPERIMENTAL SET-UP}

The GMAW experiments in short-circuiting mode were done with a $\mathrm{CO}_{2}-\mathrm{Ar}$ mixed shielding gas $\left(18 \% \mathrm{CO}_{2}-\right.$ $82 \%$ Ar; gas flowrate, $101 / \mathrm{min})$ and thin sheets $(1 \mathrm{~mm}$; mild steel). The transistorized power source (secondary chopper type) was set to $18 \mathrm{~V}$. The wire had a diameter of $1 \mathrm{~mm}$, the wire feed rate was $4.0 \mathrm{~m} / \mathrm{min}$ and the welding speed was $76 \mathrm{~cm} / \mathrm{min}$. Welding was done in an overlapped joint, as it is normal practice in the automotive industry.

The computer aided monitoring and analysing system, Analysator Hannover AH XV [4], was used for data acquisition and data processing. Figure 1 gives the block diagram of the experimental set-up. The AH XV consists of an industrial personal computer (Intel Pentium central processing unit) with a high-performance analogue-todigital converter board and special software. The voltage channel of the AH XV was connected to the welding torch (electrode) and the base metal (workpiece) by the low-pass filter with voltage divider and peak clipper. A compensated Hall effect sensor (current sensor) fed the current channel of the AH XV by a coaxial cable.

The measuring time was set to $10 \mathrm{~s}$ for each welding test. During this time, 2000000 samples of the transient voltage and current values were quasi-simultaneously captured and on-line processed into PDDs and CFDs.

The present investigation is based on 48 welding experiments. The purpose was to perform undisturbed and intentionally disturbed welds. These data were used for training and testing different automatic quality determination systems. In reference to an ideal undisturbed welding set-up the simulated welding disturbances are characterized as follows:

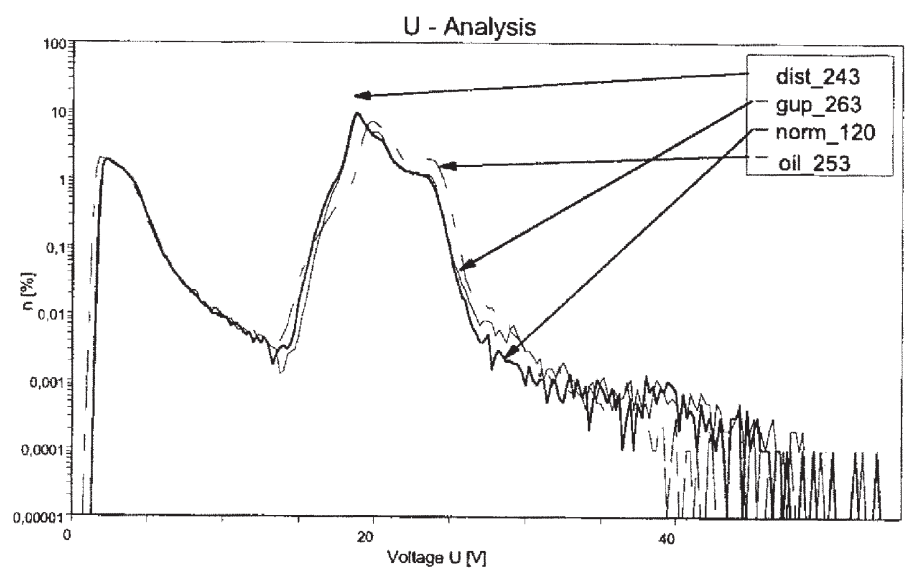

Fig. 2 Voltage PDDs 


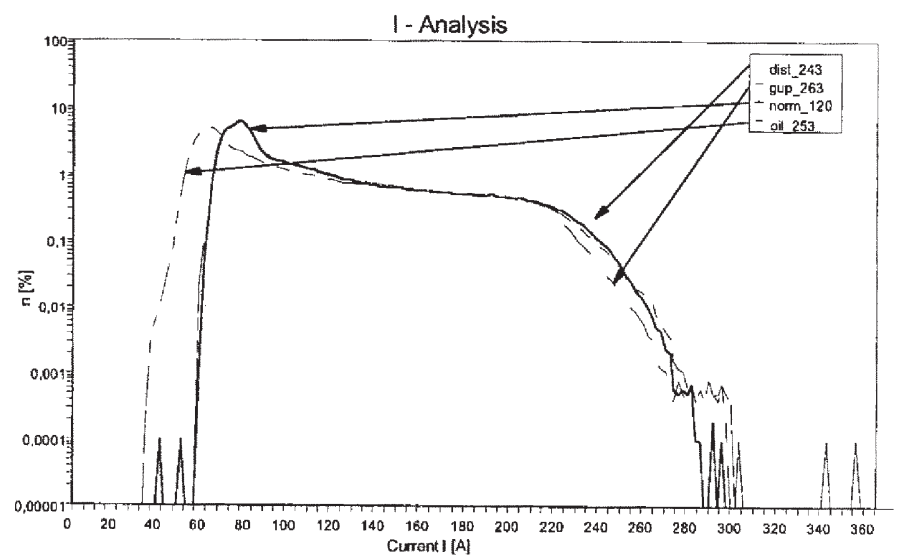

Fig. 3 Current PDDs

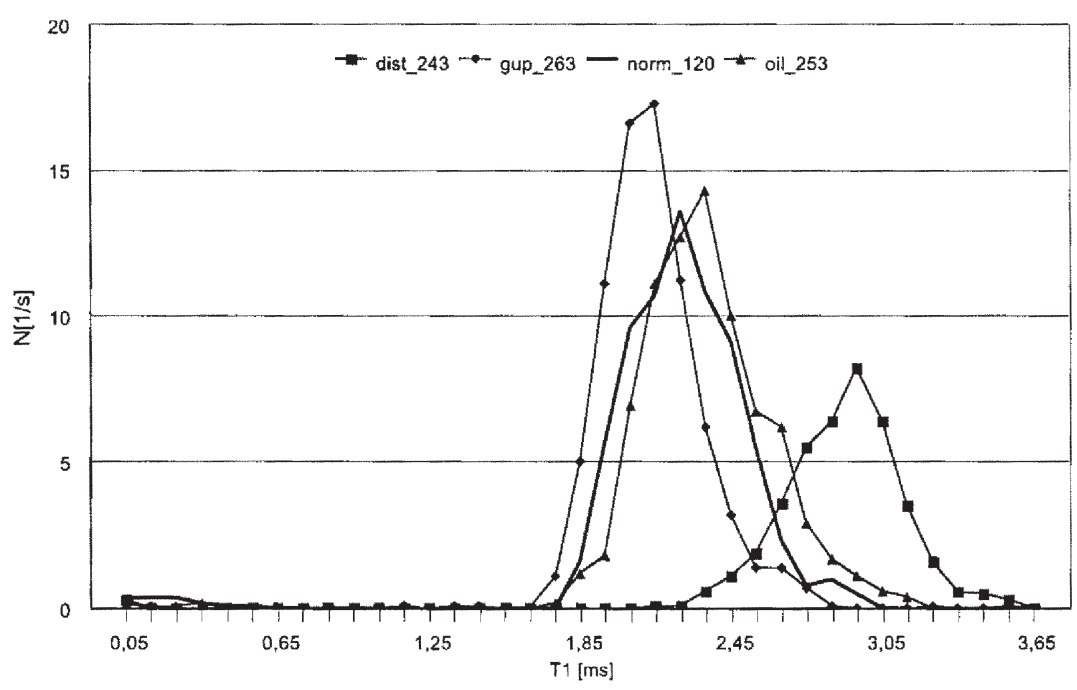

Fig. 4 Short-circuiting time $T_{1}$ CFDs

No. 1. Normal (reference).

No. 2. Increased wire feed rate.

No. 3. Decreased wire feed rate.

No. 4. Increased gas nozzle diameter.

No. 5. Welding over two sheets (bead-on-plate, no overlap).

No. 6. Welding an overlapped joint with an air gap between the upper and lower sheet.

No. 7. Oily workpiece surface.

No. 8. Welding two sheets in overlap, upper sheet with notch.

Figures 2 to 4 demonstrate the superposition of welding voltage and current PDDs as well as the CFDs of the short-circuiting time at different process disturbances (dist, disturbance No. 6; gup, disturbance No. 8; norm, reference; oil, disturbance No. 7).

\section{FEATURE EXTRACTION}

As shown in Figs 2 to 4 , the curves of PDDs and CFDs are different for various disturbances, but they are not sufficiently different. Further extraction of the features hidden in the values of PDDs and CFDs should be carried out to distinguish the types of disturbance clearly. Statistical processing of the values of voltage PDDs, current PDDs, short-circuiting time CFDs and arc-burning time CFDs was carried out to obtain further characteristics for different welding conditions:

$$
\text { Mean } \quad M=\frac{1}{N} \sum_{n=1}^{N} x_{n}
$$

Variance $\quad V=\frac{1}{N-1} \sum_{n=1}^{N}\left(x_{n}-M\right)^{2}$

Standard deviation $\mathrm{SD}=\sqrt{V}$

where $N$ is the number of sampled data and $x_{n}$ is the variable processed.

The values of mean, variance and standard deviation for PDDs of voltage $U$, PDDs of current $I$, CFDs of short-circuiting time $T_{1}$, and CFDs of arc-burning time 
Table 1 EC12 under different conditions

\begin{tabular}{llllllllllrrr}
\hline Test & $U_{\mathrm{M}}$ & $U_{\mathrm{V}}$ & $U_{\mathrm{SD}}$ & $I_{\mathrm{M}}$ & $I_{\mathrm{V}}$ & $I_{\mathrm{SD}}$ & $T_{1 \mathrm{M}}$ & $T_{1 \mathrm{~V}}$ & $T_{1 \mathrm{SD}}$ & $T_{2 \mathrm{M}}$ & $T_{2 \mathrm{~V}}$ & $T_{2 \mathrm{SD}}$ \\
\hline $1-1$ & 1.85 & 8.747 & 2.96 & 0.435 & 0.959 & 0.98 & 6.18 & 243.3 & 15.60 & 1.85 & 8.75 \\
$2-1$ & 0.83 & 5.442 & 2.33 & 0.463 & 0.777 & 0.88 & 7.03 & 288.6 & 16.99 & 2.11 & 12.22 \\
$3-1$ & 0.82 & 6.876 & 2.62 & 0.435 & 1.068 & 1.03 & 5.57 & 226.1 & 15.04 & 1.65 & 4.925 \\
$4-1$ & 0.83 & 5.907 & 2.43 & 0.435 & 0.889 & 0.94 & 6.26 & 232.4 & 15.25 & 1.88 & 11.03 & 3.22 \\
$5-1$ & 0.83 & 7.398 & 2.72 & 0.465 & 0.937 & 0.97 & 6.89 & 334.6 & 18.29 & 2.07 & 11.09 & 3.33 \\
\hline
\end{tabular}

$T_{2}$ constitute the following 12-dimensional array of characteristics:

$$
\begin{aligned}
\mathrm{EC} 12= & \left(U_{\mathrm{M}}, U_{\mathrm{V}}, U_{\mathrm{SD}}, I_{\mathrm{M}}, I_{\mathrm{V}}, I_{\mathrm{SD}}, T_{1 \mathrm{M}}, T_{1 \mathrm{~V}},\right. \\
& \left.T_{1 \mathrm{SD}}, T_{2 \mathrm{M}}, T_{2 \mathrm{~V}}, T_{2 \mathrm{SD}}\right)
\end{aligned}
$$

Each welding case should have its own EC12 which contains the essential information on the values of PDDs and CFDs in a definite integral way. Table 1 shows EC12 for different GMAW tests.

In order to demonstrate the difference in EC12 more clearly, the curves of EC12 for eight types of test are shown in Fig. 5. It should be noted that the normalization of data over the range $[0,1]$ has been carried out to avoid the weighted effect of some big data and to consider the effect of small data.

\section{AUTOMATIC RECOGNITION}

Although the curves of EC12 demonstrate a clear difference for welding process tests, a reliable recognition of these curves depends on the expert's skill. The purpose of this research is to develop an intelligent system that can recognize the process disturbances automatically and reliably without requiring expert knowledge. Figure 6 shows the block diagram of the developed intelligent recognition system, which concerns the following three methods.

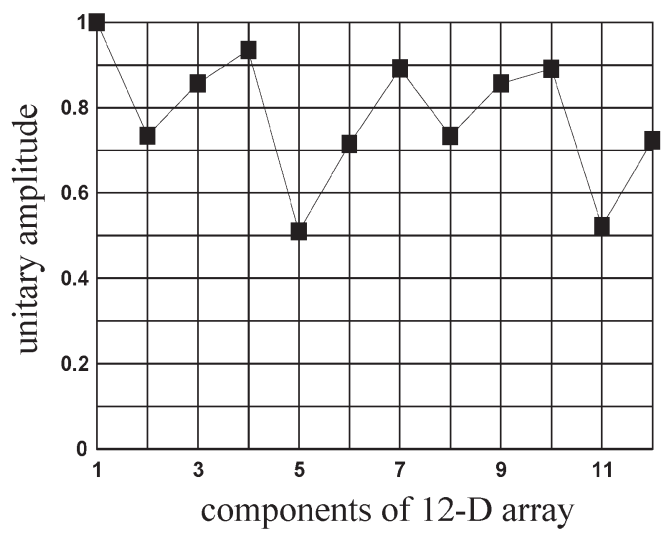

(1) No.1 Normal (reference)

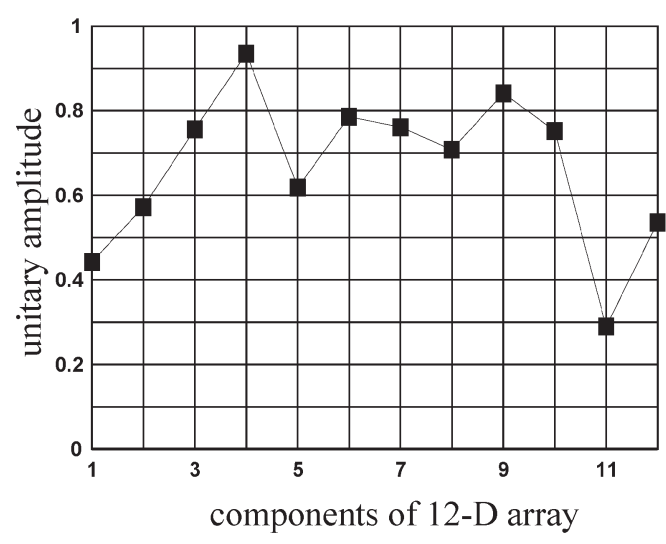

(3) No.3 Decreased wire feed rate

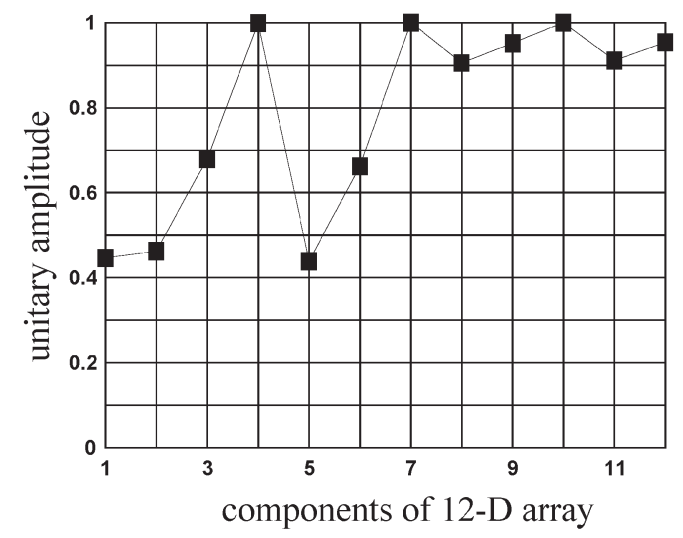

(2) No.2 Increased wire feed rate

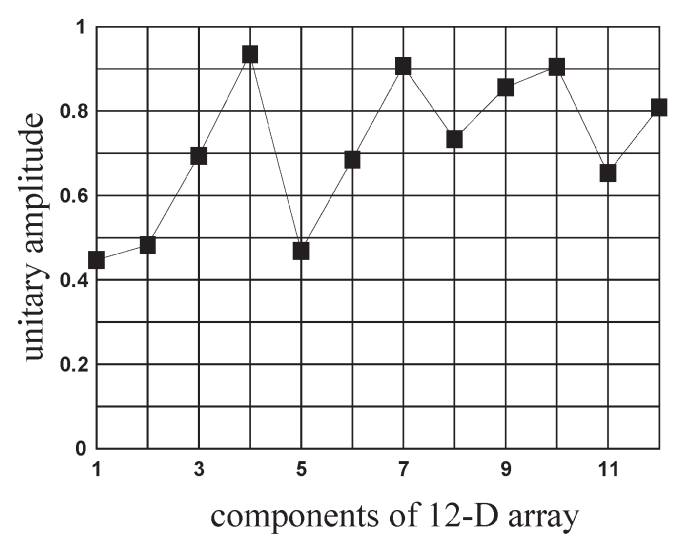

(4) No.4 Increased gas nozzle diameter

Fig. 5 (continued over) 


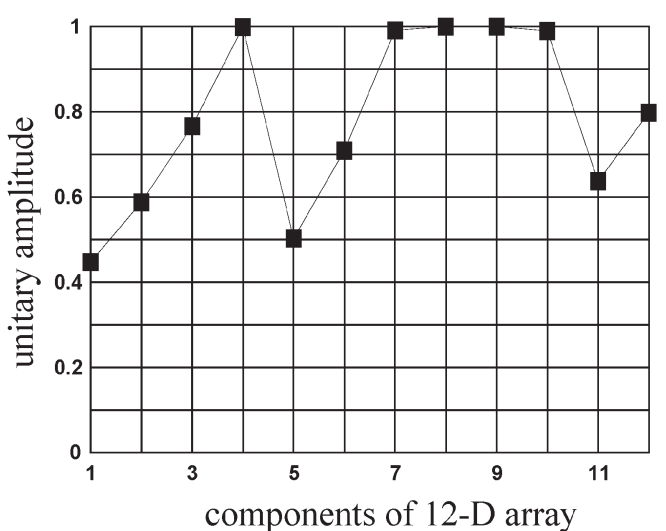

(5) No.5 Welding over two sheets

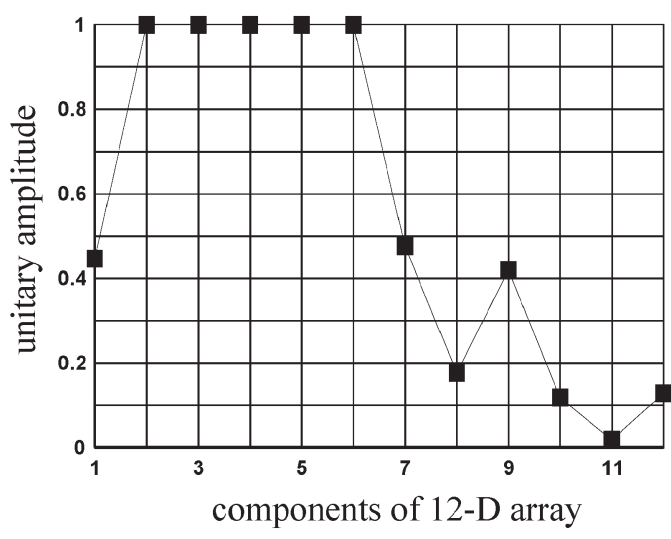

(7) No.7 Oily workpiece surface

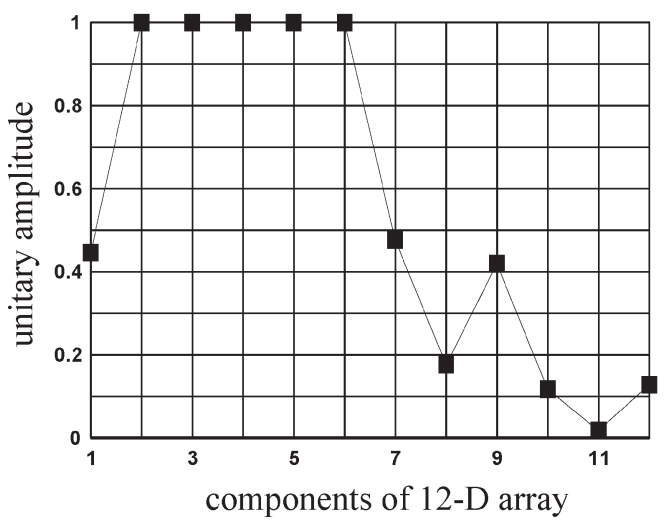

(6) No.6 Welding an overlapped joint with air gap

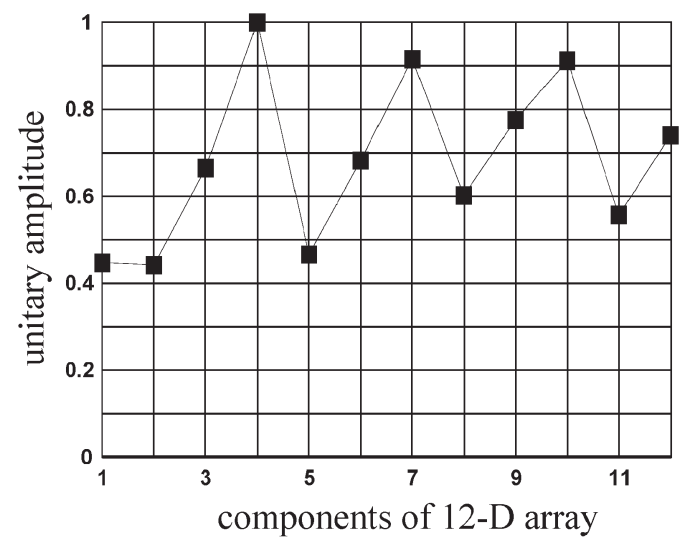

(8) No.8 Welding two sheets in overlap, upper sheet with notch

Fig. 5 EC12 under different welding conditions

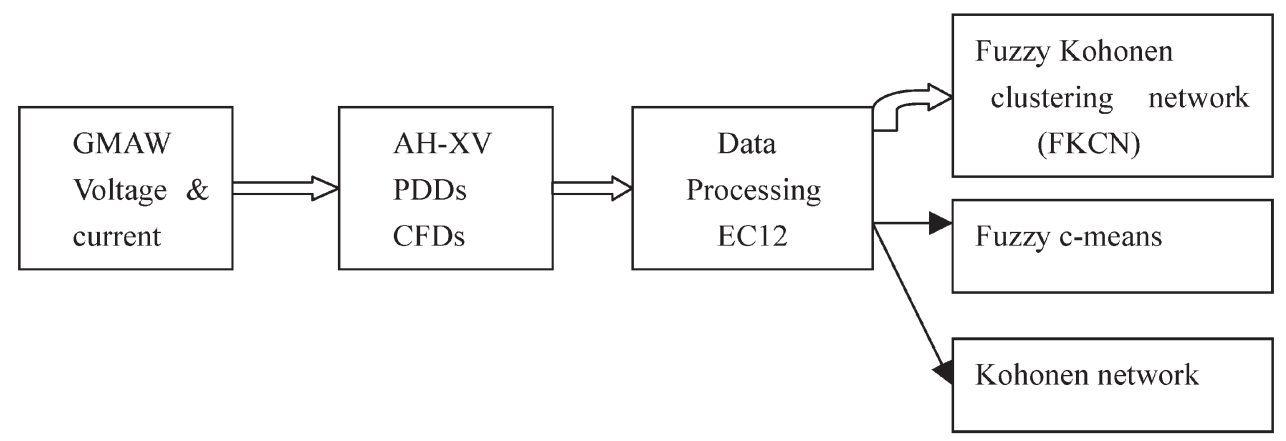

Fig. 6 Block diagram of the intelligent system

\subsection{Fuzzy c-means}

Fuzzy c-means (FCM) is a fuzzy cluster method and is thus suitable for classification tasks. It determines the class prototypes for an existing data set and a specified number of classes. Each of the so-called cluster centres represents a typical object for one class. The FCM algorithm assigns a classification of 0 to 1 between each object to be classified and each class. That means the memberships of all objects to the clusters are calculated for each cluster. In this case, there are eight welding conditions to be recognized. Therefore the structure of FCM subsystem includes four steps: clustering (training), labelling, testing (validating) and recalling (applying).

\subsection{Kohonen network}

The Kohonen network (self-organizing feature map) is an unsupervised learning neural network. It can be 
used to solve classification tasks and to find structures in data. It is able to organize independently a set of input patterns into classes. The detailed structure and algorithm of the Kohonen network may be referred to in reference [12].

\subsection{Fuzzy Kohonen clustering network}

The fuzzy Kohonen clustering network $(\mathrm{FKCN})$ is a neuro-fuzzy model in which a self-organizing Kohonen artificial neural network is combined with FCM algorithms. The goal of combining both together is to take advantage of the benefits offered by both individual methods and to compensate for each other's shortcomings. The idea behind this is that the learning rate is replaced by membership values and in this way the FCM algorithm is combined with the structure and adaptive rules of the Kohonen network. The training algorithm of FKCN is as follows:

Step 1. Initialize elements $w_{i j}$ of the weights vector $w_{i}$ using random numbers, $m(t=0)=m_{0}$.

Step 2. Calculate for each input vector $x_{k}$ the membership $u_{i k}(t)$ to the individual neurons:

$$
\begin{array}{r}
u_{i k}(t)=\frac{1}{\sum_{j=1}^{c}\left(\left\|x_{k}-w_{i}(t)\right\| /\left\|x_{k}-w_{j}(t)\right\|\right)^{2 /[m(t)-1]}}, \\
\forall i=1, \ldots, c, \quad \forall k=1, \ldots, K
\end{array}
$$

where $K$ is the number of training examples and $c$ is the number of neurons in the network. Calculate the learning rate $\alpha_{i k}(t)$ using these membership values:

$\alpha_{i k}(t)=\left[u_{i k}(t)\right]^{m(t)}$

Step 3. Adjust the weight vectors $w_{i}$ such that

$$
\begin{array}{r}
w_{i}(t+1)=w_{i}(t)+\frac{\sum_{k=1}^{K} \alpha_{i k}(t)\left[x_{k}-w_{i}(t)\right]}{\sum_{j=1}^{c} \alpha_{i j}(t)}, \\
\forall i=1, \ldots, c
\end{array}
$$

Step 4. Let $m(t+1)=m(t)-\Delta m$. If $m(t+1)>1.0$ and $\|w(t+1)-w(t)\|>\varepsilon$ then go to step 2 .

It turns out that the convergence properties of the network are improved upon, far fewer training cycles being needed to complete the task. It is also true that the algorithm is very stable to changes in the exponent step parameters, with changes only having minimum effect on the training results.

$\mathrm{EC} 12$ is the input vector of the developed FKCN system which is a two-dimensional configuration with $4 \times 4$ neurons. The software DataEngine [14] is used to complete the training, labelling, testing and applying of the FKCN.

GMAW experiments were conducted under eight

\begin{tabular}{|c|c|c|c|c|c|c|c|}
\hline \multirow{2}{*}{$\begin{array}{l}\text { Test } \\
\text { number }\end{array}$} & \multirow[b]{2}{*}{ Disturbance } & \multicolumn{2}{|c|}{ FCM } & \multicolumn{2}{|c|}{ Kohonen network } & \multicolumn{2}{|c|}{ FKCN system } \\
\hline & & Output & Correct? & Output & Correct? & Output & Correct? \\
\hline $1-4$ & \multirow[t]{3}{*}{ No. 1. Normal } & 1.0 & Yes & 1.0 & Yes & 1.0 & Yes \\
\hline $1-5$ & & 1.0 & Yes & 1.0 & Yes & 1.0 & Yes \\
\hline $1-6$ & & 1.0 & Yes & 1.0 & Yes & 1.0 & Yes \\
\hline $2-4$ & \multirow[t]{3}{*}{ No. 2. Increased wire feed rate } & 1.0 & Yes & 1.0 & Yes & 1.0 & Yes \\
\hline $2-5$ & & 1.0 & Yes & 1.0 & Yes & 1.0 & Yes \\
\hline $2-6$ & & 1.0 & Yes & 1.0 & Yes & 1.0 & Yes \\
\hline $3-4$ & \multirow[t]{3}{*}{ No. 3. Decreased wire feed rate } & 1.0 & Yes & 1.0 & Yes & 1.0 & Yes \\
\hline $3-5$ & & 1.0 & Yes & 1.0 & Yes & 1.0 & Yes \\
\hline $3-6$ & & 1.0 & Yes & 1.0 & Yes & 1.0 & Yes \\
\hline $4-4$ & \multirow[t]{3}{*}{ No. 4. Increased gas nozzle diameter } & 1.0 & Yes & 1.0 & Yes & 1.0 & Yes \\
\hline $4-5$ & & 0.0 & No & 1.0 & Yes & 1.0 & Yes \\
\hline $4-6$ & & 1.0 & Yes & 1.0 & Yes & 1.0 & Yes \\
\hline $5-4$ & \multirow[t]{3}{*}{ No. 5. Welding over two sheets } & 1.0 & Yes & 1.0 & Yes & 1.0 & Yes \\
\hline $5-5$ & & 1.0 & Yes & 1.0 & Yes & 1.0 & Yes \\
\hline $5-6$ & & 1.0 & Yes & 0.0 & No & 1.0 & Yes \\
\hline $6-4$ & \multirow{3}{*}{$\begin{array}{l}\text { No. } 6 \text {. Welding an overlapped joint } \\
\text { with air gap between the upper and } \\
\text { lower sheets }\end{array}$} & 1.0 & Yes & 1.0 & Yes & 1.0 & Yes \\
\hline $6-5$ & & 1.0 & Yes & 1.0 & Yes & 1.0 & Yes \\
\hline $6-6$ & & 1.0 & Yes & 1.0 & Yes & 1.0 & Yes \\
\hline $7-4$ & \multirow[t]{3}{*}{ No. 7. Oily workpiece surface } & 1.0 & Yes & 1.0 & Yes & 1.0 & Yes \\
\hline $7-5$ & & 1.0 & Yes & 1.0 & Yes & 1.0 & Yes \\
\hline $7-6$ & & 1.0 & Yes & 1.0 & Yes & 1.0 & Yes \\
\hline $8-4$ & \multirow{3}{*}{$\begin{array}{l}\text { No. 8. Welding two sheets in overlap, } \\
\text { upper sheet with notch }\end{array}$} & 1.0 & Yes & 1.0 & Yes & 1.0 & Yes \\
\hline $8-5$ & & 1.0 & Yes & 1.0 & Yes & 1.0 & Yes \\
\hline $8-6$ & & 1.0 & Yes & 1.0 & Yes & 1.0 & Yes \\
\hline \multicolumn{2}{|c|}{ Correct recognition rate } & \multicolumn{2}{|c|}{$23 / 24=96 \%$} & \multicolumn{2}{|c|}{$23 / 24=96 \%$} & \multicolumn{2}{|c|}{$24 / 24=100 \%$} \\
\hline
\end{tabular}
conditions, i.e. one normal condition without any disturbance and seven conditions with intentional disturbances.

Table 2 Recognition results based on EC12 
For each welding condition, six welding experiments were carried out. Input vectors EC12 from the data of the first three experiments were used to train and label the FKCN, and those from the data of three further experiments were used to test the developed FKCN. As shown in Table 2, for all the 24 experiments, the FKCN system recognizes all cases completely. The FCM system and the Kohonen network can automatically recognize 23 cases correctly. The recognition rates for $\mathrm{FKCN}$ are 100 per cent.

\section{CONCLUSIONS}

A neuro-fuzzy system FKCN for process monitoring and disturbance recognition in GMAW is developed. The values of mean, variance and standard deviation for PDDs of voltage, PDDs of current, CFDs of short-circuit time and CFDs of arc-burning time are used to constitute a 12-dimensional vector EC12 of characteristics for describing various welding conditions. A certain welding case has its own EC12 containing the essential information on the values of PDDs and CFDs in a definite integral way. GMAW experiments under eight conditions, i.e. one normal condition without any disturbance and seven conditions with intentional disturbances, are employed to train and test the FKCN system. The FKCN system successfully recognizes all the 24 cases correctly.

\section{REFERENCES}

1 Welding Handbook, Vol. 2, Welding Processes, 8th edition, 1991 (American Welding Society, Miami, Florida).

2 Esser, W. G. and Walter, R. Heat transfer and penetration mechanisms with GMA and plasma-GMA welding. Weld. $J ., 1981, \mathbf{6 0}(2), 37 \mathrm{~s}-42 \mathrm{~s}$.
3 Amin, M. Pulse current parameters for arc stability and controlled metal transfer in arc welding. Metal Construction, 1983, 15, 272-278.

4 Lin, M. L. and Eagar, T. W. Pressure produce by gas tungsten arcs. Metall. Trans. B, 1986, 17, 601-607.

5 Zhang, Y. M., Liguo, E. and Walcott, L. Robust control of pulsed gas metal arc welding. Trans. ASME, J. Dynamic Systems, Measmt, Control, 2002, 124(2), 281-289.

6 Zhang, Y. M., Liguo, E. and Kovacevic, R. Active metal transfer control by monitoring excited droplet oscillation. Weld. J., 1998, 77(9), 388s-395s.

7 Zhang, Y. M. and Li, P. J. Modified active control of metal transfer and pulsed GMAW of titanium. Weld. J., 2001, 80(2), 54s-61s.

8 Pandey, S., Rao, U. R. K. and Aghakhani, M. Metal transfer and $V-I$ transients in GMAW of aluminum. In Trends in Welding Research, Proceedings of the International Conference, Gattlinburg, Tennessee, 5-8 June 1995.

9 Quinn, T. P., Smith, C., McCowan, C. N., Blachowiak, E. and Madigan, R. B. Arc sensing for defects in constantvoltage gas metal arc welding. Weld. J., 1999, 78(9), 322s$328 \mathrm{~s}$.

10 Rehfeldt, D. and Polte, T. Monitoring systems: algorithms and systems presented at recent welding conferences. IIW Document XII-1598-99, International Institute of Welding, 1999.

11 Rehfeldt, D. and Polte, T. Three systems for process monitoring, process analysis and quality determination in arc welding. In Proceedings of the International Conference on Joining of Materials (JOM-9), Denmark, 1999, pp. 277-283.

$12 \mathrm{Wu}$, C. S., Polte, T. and Rehfeldt, D. GMAW process monitoring and quality evaluation using neural network. Sci. Technol. Weld. Joining, 2000, 5(5), 324-328.

13 Wu, C. S., Polte, T. and Rehfeldt, D. A fuzzy logic system for process monitoring and quality evaluation in GMAW. Weld. J., 2001, 80(2), 33s-38s.

14 DataEngine Overview and User Manual, 1997 (MIT GmbH, Aachen, Germany). 